\title{
Self-efficacy, Emotional Regulation, Communication Competence and Public Speaking Anxiety Towards Students
}

\author{
Zefanya Relita Trisnaningati ${ }^{1 *}$, Frikson Christian Sinambela ${ }^{2}$ \\ ${ }^{1}$ Magister Psikologi Sains, UBAYA, Surabaya, Indonesia \\ ${ }^{2}$ Magister Psikologi Sains, UBAYA, Surabaya, Indonesia \\ *Corresponding author. Email s154219001@student.ubaya.ac.id
}

\begin{abstract}
Public speaking anxiety (PSA) is one of the most common forms of anxiety disorder, with about one in five individuals experiencing this level of anxiety. Students undergoing the learning process, especially before the final examination period, can experience this anxiety disorder. The factors mentioned can be related to the emergence of public speaking anxiety, namely self-efficacy, emotional regulation, and individual communication competence. Self-efficacy is an individual's belief in his ability to complete tasks. Emotional regulation is an individual's ability to regulate the emotions experienced, and communication competence is a skill that individuals have in terms of speaking. This study aims to develop insight into self-efficacy, emotional regulation, and communication competence with public speaking anxiety in final year students who complete their final project or thesis. With this research, it is expected that several approaches will be proposed that can help students develop soft-skills in complementing the skills to convey ideas in public.
\end{abstract}

Keywords: "Public Speaking Anxiety”, "Self-efficacy”, “Emotional regulation”, “Communication competence”.

\section{INTRODUCTION}

The ability to speak in public is considered one of the general competencies a student needs to have [1]. The development of speaking skills is often neglected more than the development of reading and writing skills. In practice, students are often required to communicate or present their knowledge or ideas [1].

Research on students conducted by [2] shows that early year students are prone to experiencing social anxiety at significant risk of social and emotional problems. This study indicates that students who experience social anxiety tend to stop their studies in the next semester. Students who experience anxiety tend to show a passive attitude, lack of interest in learning, poor test results, and poor performance [3]. Supported by research related to social anxiety with 211 student subjects conducted at a university in East Java, it shows a prevalence of $22.27 \%$ experiencing anxiety disorder subjects [4].
Anxiety can be one of the motivating factors for individuals to prepare for a performance on the previous days. However, anxiety that appears suddenly before or during performance can ruin the show [5]. There are two types of anxiety, consist of trait anxiety and state anxiety. Trait anxiety is described as anxiety which is the character, nature, and permanent in individuals, while state anxiety is described as anxiety which is based on a specific pattern of events and is described as a temporary and fluctuating state [6][7]. Anxiety appears related to low self-esteem, fear of failure, or worries about individual performance [8].

One of the familiar and widely encountered anxiety is public speaking anxiety or better known as public speaking anxiety (PSA). PSA is a derivative of social anxiety experienced by many people in the US, with an estimated $11 \%$ to $30 \%$ of the US population [9]. Public speaking anxiety (PSA) is one of the most common forms of anxiety disorder, with about one in five individuals experiencing this level of anxiety 
[10]. Individuals with high social anxiety levels consistently think that other people give them negative impressions [10][11]. The PSA prevalence estimates range from $20 \%$ to $80 \%$ of the population [12]. A national survey conducted by Ruscio [12] in 2008 showed that PSA is a general social fear experienced by individuals for life with a rate of $21 \%$ of the sample.

Given the prevalence in society, it can be concluded that social anxiety is still an important aspect that needs attention. To reduce and avoid social anxiety's adverse effects, especially PSA, individuals need to adjust their anxiety levels to achieve success in public speaking. Students' PSA could impact short-term and long-term performance in the classroom [13]. PSA is an aspect that can be controlled and not to be cured. In this study, the PSA referred to is social anxiety that arises in specific situations, namely when individuals perform oral presentations.

Referring to several studies that have been conducted, overcoming anxiety in individuals will be different from one another, depends on the individual's assessment of their respective abilities or self-efficacy [14]. Self-efficacy is an individual's belief in his ability to behave, leading to the expected results [15]. Individuals with high self-efficacy can plan and complete tasks well [16]. Self-efficacy is also associated with motivation and behaviour change to increase the influence of regulation and psychosocial function on individuals [17]. Low selfefficacy is associated with wrong coping strategies in social situations that can increase social anxiety [17]. Wrong and excessive self-efficacy can cause dysfunction of self-efficacy, which results in individuals overestimating their ability to accomplish something. Tasks and instead leads to failure or underestimating one's abilities [18]. In the context of this study, when individuals have a high level of selfefficacy, the individual can provide good performance at the time of presentation. Self-efficacy can mediate the anxiety experienced by individuals [19]. Self-efficacy itself has been shown to improve performance, especially in academics [19].

Another aspect that assumes able to reducing PSA is emotional regulation. In terms of public speaking, emotional regulation is considered a factor in reducing an individual's PSA to excellent performance. Emotional regulation is defined as a control process that changes the character or intensity of emotional experiences [20]. Emotional regulation is generally considered a conscious effort by an individual to change the felt and automatic emotions and incidental. Emotional regulation can also be interpreted as an individual's ability to control his emotional response depending on the individual's goals that reduce, intensify, or maintain emotional responses [21]. The importance of emotional regulation as an individual control to regulate and survive on emotions in everyday life is inevitable [20]. The research results conducted [9] show fear reactions and avoid labelling their emotional experiences and making these experiences a hostile and threatening stimulus. Concerning PSA, when individuals deliberately avoid attention from social stimuli, this is assumed to be a maladaptive strategy controlled by the individual for emotional regulation, which will sustain the anxiety [22]. individuals with low emotional regulation will show avoidance as much as possible [23]. Experience and avoidant behaviour are two separate components of anxiety [23]. Avoidance based on individual experiences focuses on the individual's internal experiences, such as thoughts, emotions, and physiological sensations. In comparison, avoidance behaviour focuses on individual external experiences such as social situations, public speaking, and meetings and gatherings that involve many people [23].

When they perform on public speaking, individuals know and realize that their behaviour is being observed and evaluated. Social anxiety in individuals increases when faced with situations where others will be judged $[10 ; 21]$. Labels provided by the audience can be one of the stimuli for individuals, including emotional experience labels, characteristic labels, or labels regarding their emotions during their public speaking experience [21]. Research conducted found that labelling by the audience during public speaking can increase individual physiological responses, especially for individuals who experience anxiety related to negative labels. When speaking in public, labelling can be a stimulus for individuals regarding negative experiences with public speaking that lead individuals to experience PSA [9]. This is reinforced based on [21] research, individuals with PSA have less effective emotional regulation than individuals who do not experience PSA. Individuals with PSA have more negative cognition and less positive cognition, as well as public speaking. Also, individuals with PSA experience more stress and 
negative images, which show evidence that emotional regulation impacts negative stimuli that are not associated with social rejection [21]. Based on the explanation above, it leads to the conclusion that emotional regulation affects individual PSA.

Other research shows that one of the factors that can influence PSA is communication competence. PSA occurs because individuals lack the required skills [24]. Along with the development of PSA research, the results show that PSA is learning from experience [24]. PSA occurs due to an individual's negative experiences in the past [24]. The manifestation of these negative experiences becomes a strong tendency for individuals to think negative thoughts that interfere with their ability to pay attention to speaking ability [24]. These negative thoughts impact decreasing individual competence because individuals will focus more on the feedback provided by the audience [24]. Wismer [25] said that a speaker must be competent in delivering content. Speakers need to understand their audience and be well prepared. Besides, the speaker's verbal and nonverbal communication competence is a factor in public speaking performance's success or failure.

Public speaking competencies consist of knowledge, motivation, and abilities [26]. Knowledge includes individual mastery of stage situations (procedural knowledge) and knowledge related to understanding the presented (content knowledge). Knowledge in communication directs individuals to convey what will be conveyed and what is done and its procedures. Content knowledge is an individual's understanding of topics, sentences, the meaning of what will be conveyed. Procedural knowledge directs individuals to be able to arrange, plan to convey content knowledge in certain situations. Individual motivation consists of positive motivation and negative motivation. On negative motivation, individuals will experience anxiety, thoughts of the potential not to appreciate others, and previously unimaginable situations [26].

In contrast, individual positive motivation is the individual's perception of benefiting from the communication process. This is what encourages individuals to get satisfactory results in doing public speaking. One of the essential keys in communication is finding self-motivation to communicate better than what has been done so far. In communication, the individual will determine two things, namely, approach or avoidance. Usually, individuals will approach certain situations and tend to avoid other situations. Individual motivation to avoid certain situations is based on anxiety or fear of something that has been anticipated. In line with what was conveyed, that individuals tend to avoid situations related to self-presentation as a form of their selfdefence [10][23].

Overall, individual performance in doing public speaking depends on the motivation and knowledge of each individual. However, the main thing is individuals' behaviour and abilities, which are usually interpreted as competent or incompetent [26].

Based on the description above, this study to develop insight into self-efficacy, emotional regulation, and communication competence to PSA towards final year students. This study's urgency refers to the prevalence of anxiety, especially social anxiety, and, more specifically, PSA, which is an activity that is close to student life but is still a common problem experienced by students. With this research, it is hoped that it can provide a new reference for reducing PSA levels in individuals, especially students.

\section{METHOD}

A literature study was conducted to collect data that met the research requirements. The research was conducted using several journal data sources such as "Google Scholar," "Science-Direct," "Emerald Insight," "Routledge Publisher," "Frontiers in Psychology," "Plos One," "International Journal of Science and Research (IJSR)." Researchers examined research journals involving related variable selfefficacy, emotional regulation, communication competence, anxiety, social anxiety, public speaking anxiety, speech anxiety. The keywords used are "Public Speaking Anxiety," "Speech Anxiety," "Selfefficacy and anxiety," "emotional regulation and anxiety," "competence and public speaking anxiety." Keywords are used independently or in combination to maximize the range of literature searches.

The following steps carry out research journal screening: (1) evaluating the research title, whether it contains research variables or not, (2) examining the research abstract. Literature with appropriate abstracts was collected for further screening according to inclusion and exclusion criteria. 


\subsection{Inclusion and Exclusion}

The literature obtained was then selected based on inclusion criteria. Studies that qualify are studies that (1) have gone through a peer-review process, (2) published during the last ten years 2010-2020, and core theory (3) written in English (4) there are coefficients between related variables, self-efficacy, emotional regulation, communication competence, anxiety, social anxiety, and public speaking anxiety. Instead, to make sense of the reviewed evidence, the findings were arranged in a table that also illustrated the studies - findings from the reviews that we are concerned about self-efficacy, emotional regulation, communication competence, and public speaking anxiety.

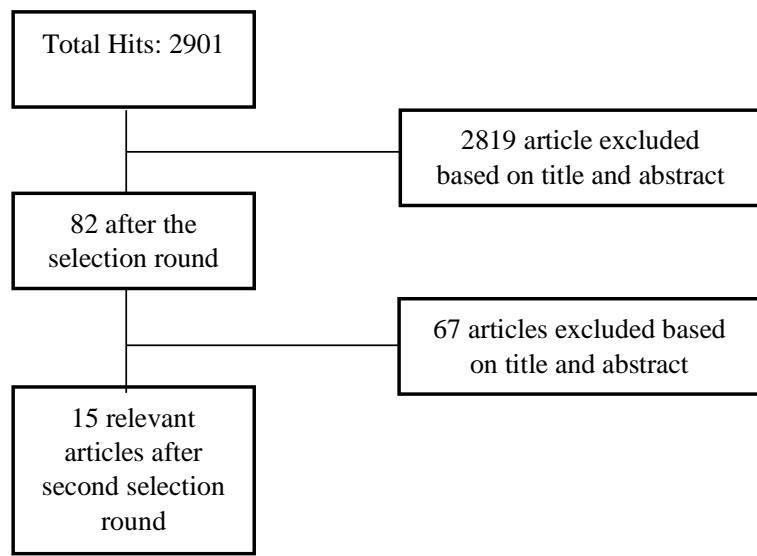

\section{RESULT}

The current study involved 15 studies consist of self-efficacy, emotional regulation, communication competence, and public speaking anxiety.

\subsection{Public Speaking Anxiety}

Various studies have been carried out relating to several external and internal factors that can affect individual PSA. Several studies with internal factors include research conducted [27] with the research results of individual traits (depression, neuroticism, sensitivity to punishment, and harm avoidance) play an essential role in responding to fearful situations for individuals.

Several other studies with external factors affecting PSA. The results of research conducted show that when individuals have positive perceptions, it has a positive impact on the dimensions of individual public speaking skills [1].
Audience situations and settings can also play a role as an external factor that affects individual PSA [28].

\subsection{Self-Efficacy and Public Speaking Anxiety}

There are three studies related to self-efficacy and public speaking anxiety with descriptive statistical measurement methods using Motivated Strategies for Learning Questionnaires (MSLQ), Anxiety of National Examination, and Morgan-Jinks Student Efficacy Scales (MJSES), Foreign Language Classroom Anxiety Scales (FLCAS). Based on this quantitative study results, the results of the negative correlation between self-efficacy and public speaking anxiety were obtained. The higher the individual selfefficacy, the lower the public speaking anxiety. Conversely, the lower the individual self-efficacy, the higher the public speaking anxiety $[19 ; 29 ; 30]$.

\subsection{Emotional Regulation and Public Speaking Anxiety}

There are two studies related to emotional regulation and public speaking anxiety with experimental methods. The Personal Report of Public Speaking Anxiety, Mindfulness-Based Stress Reduction (MBSR), and fMRI as measurement tools. Based on the results of this study, it was found that individuals' verbal labelling affects the emotional condition of the individual at the same time [29]. Individuals with low emotional regulation on an incident have depressive symptoms when doing public speaking [21].

\subsection{Communication Competence and Public Speaking Anxiety}

There are three studies related to communication competence and public speaking anxiety that use experimental and quantitative descriptive methods. Measuring instruments used include the Foreign Language Classroom Anxiety Scales (FLCAS), the Speaking Anxiety Scale, the Social Phobia Scale (SPS), the Social Interaction Anxiety Scale (SIAS), the Liebowitz Anxiety Scale Self Report version (LSAS-SR), and the Self Talk Scale (STS). Based on the study results, it was found that individuals with social anxiety have worse performance than individuals in the neutral group [31]. Individuals who prepare themselves before doing public speaking have a lower level of anxiety than those who do not prepare [32]. 


\subsection{Public Speaking Anxiety and Students}

Self-efficacy is one factor that affects student anxiety when facing exams [29]. The results show that self-efficacy plays an essential role in reducing student anxiety when facing national exams [29].

\subsection{Discussion}

They are related to this study's aim to develop insight into self-efficacy, emotional regulation, and communication competence to PSA to help students overcome soft skill issues to convey general ideas. According to the literature review, PSA able to be influenced by internal factors. Internal factors include research conducted, such as individual traits (depression, neuroticism, sensitivity to punishment, and harm avoidance) that play an essential role in responding to fearful situations for individuals [27]. The results of research conducted [1] show that when individuals have positive perceptions, it has a positive impact on the dimensions of individual public speaking skills.

Several variables study related to PSA, such as self-efficacy, emotional regulation, and communication competence. The research result between self-efficacy and PSA shows there is a negative correlation between self-efficacy and PSA were obtained. The higher the individual selfefficacy, the lower PSA. Conversely, the lower the individual self-efficacy, the higher the public speaking anxiety $[19 ; 29 ; 30]$. Based on the results of this study, it was found that individuals' verbal labelling affects the emotional condition of the individual at the same time [20]. Individuals with low emotional regulation on an incident have depressive symptoms when doing public speaking [21]. Finally, in several studies related to competence and public speaking anxiety, it was found that individuals with social anxiety have worse performance than individuals in the neutral group [31]. Individuals who prepare themselves before doing public speaking have a lower level of anxiety than those who do not prepare [32].

Self-efficacy is one factor that affects student anxiety when facing exams. The results show that self-efficacy plays an essential role in reducing student anxiety when facing national exams [29].

\subsection{Conclusion and limitation}

According to several previous studies, it is known that self-efficacy plays an essential role in reducing individual anxiety levels. Based on other literature reviews, another internal factor that can reduce anxiety levels is the individual's ability to regulate emotions regarding experiences related to specific situations. Concerning the objectives of this study, students need to have self-efficacy and emotional regulation to make presentations. Apart from selfefficacy and emotional regulation, communication competence is something that students need to develop to support their presentations. From the literature review, communication competence plays a role in reducing the level of public speaking anxiety.

This review has several limitations. Considering the small number of studies included and the methodological issues described, the findings should be treated with caution. This applies especially to the results on self-efficacy, emotional regulation, and communication competence toward PSA. Therefore, all comments made about this are preliminary and warrant further investigation in future research.

This review suggests that future research into the effects is needed. The number of studies on this topic is too small when considering the urgent and evident need. The number of prevalence might change and research updates related to social anxiety. More empirical research using reliable and valid instruments into social anxiety and PSA is required. Furthermore, explore possibility influencing factors to PSA need for observational and research on this topic.

\section{AUTHORS' CONTRIBUTIONS}

The development of this research, ZRT create the idea of the study, drafted, edited the manuscript and interpreted the results; analysed the data, compiled data resources; FCS oversaw the study, created the idea for the study, guided the writing of the manuscript. All authors have read and approved of the manuscript.

\section{ACKNOWLEDGMENTS}

The study was supported by 2020 Faculty of Psychology, University of Surabaya.

\section{REFERENCES}

[1] H. Evelin, G. Jessika, T. Maike, Z. Ingo, T. Ulritch. Putting a speech training program into practice: it's implementation and effect on 
elementary school children's public speaking skills and levels of speech anxiety. Contemp Educ Psychol. 55 (2018) 176-188

[2] A.H. Nordstorm, L.M.S. Goguen, M. Hiester. The effect of social anxiety and self-esteem on college adjustment, academics, and retention. J. Coll. Couns. 17 (2014) 48-63

[3] G. Mohammadyari. Comparative study of relationship between general perceived selfefficacy and test anxiety with academic achievement of male and female students. Procedia Soc Behav Sci. 69 (2012) 2119-2123

[4] I.K. Swasti, W. Martani. Menurunkan kecemasan sosial melalui pemaknaan kisah hidup. J. Psikol. 40(1) (2013) 39-58

[5] A.W. Brooks, J. Schroeder, J.L. Risen, F. Gino, A.D. Galinsky, M.I. Norton, M.E. Scheweitzer. Don't stop believing: rituals improve performance by decreasing anxiety. Organ. Behav. Hum. Decis. Process. 137 (2016) 71-85 DOI:10.1016/j.obhdp.2016.07.004

[6] C.D. Spielberger. Anxiety and behavior. New York: Academic Press Inc.; 1966

[7] J. Wilt, K. Oehlberg, W. Revelle. Anxiety in personality. Pers. Individ. Differ. 50 (2011) 987993. DOI: 10.1016/j.paid.2010.11.014

[8] P.K. Kankam, S.O. Boateng. Addressing the problem of speech anxiety among students. Int. J Pub Leadersh. 2016 Dec; 13:(1): 26-39. DOI: 10.1108/IJPL-07-2016-0029

[9] A.N. Niles, M.G. Craske, M.D. Lieberman, C. Hur. Affect labeling enhances exposure effectiveness for public speaking anxiety. Behav. Res. Ther. 63 (2015) 27-36. DOI: 10.1016/j.brat.2015.03.004

[10] M. Leary, R. Kowalski. Social phobia: diagnosis, assessment, and treatment. Ed Heimberg, R., Liebowitz, M., Hope, D., Schneier, F. The Self-Presentation Model of Social Phobia. New York: The Guilford, p. 94. 1995

[11] E. Nelson, B. Deacon, J. Lickel, J. Sy. Targeting the probability versus cost of feared outcomes in public speaking anxiety. Behav. Res. Ther. 48
(2010) 282-289. DOI:

10.1016/j.brat.2009.11.007

[12] E.L. England, J.D. Herbert, E.M. Forman, S.J. Rabin, A. Jurascio, S.P. Goldstein. Acceptancebased exposure therapy for public speaking anxiety. J Contextual Behav Sci. 2012 Jul; 1:6672. DOI: $10.1016 /$ j.jcbs.2012.07.001

[13] A.H Kamridah,. B, Yassi,. N. Arafah. Imran. Correlation between level of anxiety and public speaking performance through systematic learning approach in foreign language. Int. J. Sci. Res. (IJSR). 2016 Sep; 5:9:1658-1663. DOI: 10.21275/ART20161991

[14] D. Paradewari. Investigating student's selfefficacy of public speaking. Int. J.Educ.Res. 5 (2017) 10:97-108.

[15] W. Weiten. Psychology: themes and variations $9^{\text {th }}$ Ed. USA: Wadsworth Cengage Learning, Belmont CA; 2013.

[16] A. Ahmad, T. Safaria. Effects of self-efficacy on student's academic performance. J. Educ, Health, Comm Psychol. 2(1) (2013) 22-29. DOI: 10.13140/RG.2.1.3281.4487

[17] I. Iancu, E. Bodner, B. Itzhak. Self esteem, dependency, self-efficacy, and self-criticism in social anxiety disorder. Compr. Psychiatry 58 (2015) 165-171. DOI: 10.1016/j.comppsych.2014.11.018

[18] S. Razavi, A. Shahrabi, H. Siamian. The relationship between research anxiety and selfefficacy. Mater Sociomed. 29(4) (2017) 247250. DOI: $10.5455 / \mathrm{msm} .2017 .29 .247-250$

[19] J. Barrows, S. Dunn, C. Lloyd. Anxiety, selfefficacy, and college exam grades. Universal J. Educ.Res. 1(3) (2013) 204-208.

[20] L.J. Burklund, J.D. Creswell, M.R. Irwin, M.D. Lieberman. The common and distinct neural bases of affect labeling and reappraisal in healthy adults. Front. Psychol. 5(22) (2014) 110. DOI: $10.3389 /$ fpsyg.2014.00221.

[21] A.N. Niles, M.G. Craske. Incidental emotion regulation deficit in public speaking anxiety. Cognit Ther Res. 8 (2018) DOI: 10.1007/s10608-018-9954-1 
[22] M. Lin, M. Qian, D. He, X. Wen, X. Li. Avoidance all of feedback? Attention allocation during and after public speech in social anxiety. J Behav Ther Exp Psychiatry. 66 (2020) 1-7. DOI: $10.1016 /$ j.jbtep.2019.101520.

[23] B. Mesri, A. Niles, A. Pittig, R. LeBeau, E. Haik, M. Craske. Public speaking avoidance as a treatment moderator for social anxiety disorder. J Behav Ther Exp Psychiatry. 55 (2017) 66-72. DOI: 10.1016/j.jbtep.2016.11.010.

[24] G.D. Bodie. A racing heart, rattling knees, and ruminative thoughts: defining, explaining, and treating public speaking anxiety. Commun. Educ. 59(1) (2010) 70-105. DOI: $10.1080 / 03634520903443849$

[25] N.K. Mehta. Enhancing engineers' public speaking efficacy using appreciative inquiry. Ind. Commer. Train. 50(2) (2018) 81-94. DOI: 10.1108/ICT-05-2017-0035

[26] S.P. Morreale, B.H. Spitzberg, J.K. Barge. Communication: motivation, knowledge, skills (3rd ed.). New York, NY: Peter Lang Publishing Inc; 2013.

[27] G. Panayiotou, M. Karekla, D. Georgiou, E. Constantinou, M. Paraskeva-Siamata. Psychophysiological and self-reported reactivity associated with social anxiety and public speaking fear symptoms: effects of fear versus distress. Psychiatry Res. 255 (2017) 278-286. DOI: 10.1016/j.psychres.2017.05.044

[28] Z. Suleimenova. Speaking anxiety in a foreign language classroom in kazakhstan. Procedia Soc Behav Sci. 93 (2013) 1860-1868. DOI: 10.1016/j.sbspro.2013.10.131

[29] H. Qudsyi, M. Putri. Self-efficacy and anxiety of national examination among high school students. Procedia Soc Behav Sci. 217 (2016) 268-275. DOI: 10.1016/j.sbspro.2016.02.082

[30] E. Mede, O. Karaimark. The predictor roles of speaking anxiety and English self-efficacy on foreign language speaking anxiety. J. Teach. Educ. Educators (JTEE) 6(1) (2017) 117-131

[31] S. Stevens, R. Cooper, T. Bantin, C. Hermann, A. Gerlach. Feeling safe but appearing anxious: differential effects of alcohol on anxiety and social performance in individuals with social anxiety disorder. Behav. Res.Ther. 94 (2017) 918. DOI: $10.1016 /$ j.brat.2017.04.008

[32] X. Shi, T. Brinthaupt, M. McCree. The relationship of self-talk frequency to communication apprehension and public speaking anxiety. Pers. Individ. Differ. 75 (2015) 125-129. DOI: 10.1016/j.paid.2014.11.023 